\title{
The Relationship Between the Mid-Level Leader and Follower Commitment
}

\author{
Linda J. Burrs, (Email: linda@step-up-to-success.org), University of Phoenix
}

\begin{abstract}
The major goal of this research was to determine whether the mid-level leader's emotional competence as perceived by followers influenced commitment. This quantitative research study attempted to establish whether follower commitment, influenced by follower perceptions of the leader's emotional competence impacted change strategies. Correlation testing of the data indicated a strong relationship between the mid-level leader's emotional competence and follower commitment. Results of the research suggest that as organizations continue to experience high levels of change, modifications in how the psychological contract is negotiated between mid-level leaders and their followers have created the need for a new paradigm shift. This justified shift may be needed to move from archaic forms of organizational commitment theory to a follower commitment theory that encourages higher levels of follower involvement in and commitment to leader-led vision and goals.
\end{abstract}

\section{INTRODUCTION}

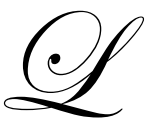

eaders are expected to lead in the face of many complex issues, one of the most significant being change. In the last ten years, approaches to leading organizational change has evolved drastically due in great part to a major shift in how leaders lead and how followers follow. This is a study about leadership, change, and commitment from the follower's perspective. Follower commitment, as used in the context of this work, is an emerging field of leadership study.

\section{PROBLEM STATEMENT}

Regardless of the industry, there appears to be a lack of commitment to leader-led change initiatives. According to a three-year study by Werhane and Maitland (2002), some organizations saw operating margins fall by $3.01 \%$ and net profit margins fall by $1.38 \%$ because of uncommitted followers. This lack of commitment has been estimated to cost organizations $\$ 250$ - $\$ 350$ billion (Heffes, 2003, p. 40). Despite best efforts by leaders, change efforts continue to fail. Beer and Nohria (2000) argue as many as 70\% of all change initiatives fail (p. 133). Researchers have theorized one of the reasons for this high failure rate may be the leader's inability to release follower motivational energy to increase follower commitment. The mid-level leader's emotional competence may be a contributing factor for this lack of follower commitment and high failure rate of change programs.

This problem of the leader's inability to develop follower commitment through the generation of motivational energy has negatively influenced the competitive environment McClelland's (1973) research that found $87 \%$ of leaders with higher levels of emotional competence experienced $15-20 \%$ higher performance in revenue gains. 


\section{BACKGROUND OF THE PROBLEM}

Historically, followers appeared as invisible during early leadership theories such as Carlyle's (1841) and Galton's (1869) Great Man Theories. Lewin and Lippitt (1938) suggested employees were recognized, but leaders continued as the dominant force in the manager/employee relationship. After the Hawthorne studies (Mayo, 1949) demonstrated employees needed to feel valued and that their work mattered to them and others in authority, motivational theories increased. In spite of suggesting employees wanted and needed more involvement, control of employees increased and bases of power increased to the leader as noted in the leadership theory of French and Raven (1959). The introduction of transformational leadership by Bass' (1985) and Bennis and Nanus' (1985) work represented a change in attitude from the concept of 'employees as mindless entities incapable of contributing any more than what they were told to do', to 'followers who are capable of innovative and creative solutions'. In addition, an understanding of the psychological and emotional components of the leader/follower dyad is necessary. The continued dismissal of the need to engage employees has drained the life out of them (Lucas, 1999). Lucas also suggested that when leaders release the energy of followers, those followers develop an aroma of excitement and passion and commitment for their work.

"Organizationally speaking, energy is the force that transforms ideas into action, action into outcomes. The major source of organizational energy is people" (Kielson, 1994, p. 47). Ostwald (1903) explained, “. . . that other factor, energy, may be converted from every one of its forms into every other, and its power of transformation is therefore unlimited" (p. 311). Leaders may therefore have unlimited capability of creating their preferred future by focusing on releasing positive energy. The leader who is open to working within the organization's culture to create an internal environment that sustains the release of energy and passion will experience greater success in negating change program failures (Schwartz, 1990).

Katzenbach and Santamaria (1999) stated it would be an error in judgment to assume front line employees are "liabilities to be contained" (p. 107). They argued followers' emotional energy should be engaged. Nicholson (2003) further suggested it is the leader's responsibility to release motivational energy in order to create an environment where followers may generate a natural commitment to organizational goals. Leaders and followers who are passionately engaged in what they do are energetic and enthusiastic and it shows (Lucas, 1999).

Overton and Burkhardt (1999) suggested individuals reserve their most precious resources, energy and commitment, for the issues that are most important to them. They further argued it is the leader's responsibility to establish and continually work toward establishing commitment.

To make meaningful progress toward a vision requires a long-term commitment of energies and resources. First, the inspiration and energy that are derived from the original vision and relationships must be refreshed through reexamination and recommitment. Second, there must be a constant infusion of new enthusiasm (Overton \& Burkhardt, 1999, p. 227).

Gregersen, Morrison, and Black (1998) suggested a genuine emotional connection would lead to willingness on the part of followers to do their best work and make whatever sacrifices were required to support the leader's vision. This includes, "giving the leader the benefit of the doubt on difficult matters" (p. 24), thus releasing motivational energy. When the leader emotionally connects with followers, they are more adept in securing support during negative events. "In essence ... leaders need to have the ability to inspire and arouse their followers emotionally. Followers, thus inspired, become committed to the leaders' vision and, ultimately, to the organization" (Humphreys, Weyant \& Sprague, 2003, p. 193).

\section{LITERATURE REVIEW}

The review of relevant literature suggested organizational commitment may no longer be a practical theory for understanding how followers commit their energies, resources, and motivations. Changes in the psychological contract due to continued restructuring and re-engineering efforts, lack of trust in organizations, and changes in the attitudes and perceptions of employees, have led to a significant reduction in confidence, trust, and belief in the 
organization. This literature review examined past and present studies to explore the gap in commitment research related to follower motivation theory and follower commitment theory. It was believed the development of this follower commitment theory, through a research study, would allow a change in the contextual understanding of commitment from an organizational commitment perspective to follower commitment for leader-led initiatives and goals.

\section{Emotional Intelligence And Competence}

Trust, as a pillar of leadership, cannot be underestimated as motivation to perform. "Leaders that force performance rather than inspire, may be successful in the short term, but during times of turbulence and change, they are less effective because they have not led from vision, reality, and trust but from fear and intimidation" (Slater, 2001, p. 35).

LeDoux (1998) asserted, "Once emotions occur they become powerful motivators of future behaviors" (p. 19). What has become clearer during this study is, how an individual feels about their work and the relationships engaged in their work life significantly impacts them and their productivity. "Whether or not a person is going to give his services wholeheartedly to a group depends, in good part, on the way he feels about his job, his fellow workers, and supervisors - the meaning for him of what is happening about him" (Roethlisberger, 2001, p. 161). Leaders who develop their emotional competence discover it is through an emotional connection; opportunities to improve follower commitment are revealed (Landen, 2003).

\section{Organizational Commitment}

Mowday, Porter and Steers (1979) developed and validated an instrument that attempted to measure employee commitment to work organizations. These researchers developed the Organizational Commitment Questionnaire ${ }^{\circledR}(\mathrm{OCQ})$ to assess employee's commitment to the organization through their behaviors and attitudes. They further defined behavioral commitment as conduct that bound an employee's actions. They also defined attitudinal commitment as an employee being able to identify with the organization's goals in order to maintain membership or employment. "For the purposes of instrument development, organizational commitment was defined here as the relative strength of an individual's identification with and involvement in a particular organization" (Porter \& Smith, 1970, as cited in Mowday et al., p. 226).

It appears overall that the concept of organizational commitment ignores the synergy developed in the leader/follower dyad. In a recent study by Noble and Mokwa (1999), it was found that organizational commitment was not a factor in the relationship between leaders and followers in accomplishing organizational strategies. It is within this context this study examined the relationship between mid-level leaders' emotional competence and follower commitment overall, and more specifically, examined how the relationship between the mid-level leaders' emotional competence related to followers in support of leader-led change initiatives.

Meyers and Allen (1991) extended Mowday, Porter, and Steers' (1979) organizational commitment theory was based on attitudes and behaviors by arguing, organizational commitment was based on desires, needs, and a sense of obligation to stay with the organization. This redefined concept of organizational commitment moved commitment from the "traditional psychological state of attitude" (Meyers \& Allen, 1991, p. 63).

Landen (2003) suggested emotional commitment is necessary due to the nature of changing work environments. Landen concluded that followers are being asked to trust in spite of the fact that long-term guarantees are no longer existent; followers are also being asked to identify with the organization in spite of a loss of control in their employment relationship. What Landen does not include in her research and findings is how emotional commitment is related to identification with the leader, a distinct foci and potential object of commitment.

This research study argued that commitment extends beyond organizational commitment as supported by commitment theorists Allen and Meyer, (1990), Kanter (1985), and Mowday et al. (1979). 


\section{Follower Commitment}

Baruch (1998) suggested that the decrease in the original organizational commitment concept as a relevant theory for explaining follower behaviors appeared to be related to recent changes in how organizations treat employees. "Commitment is emotional" (Goleman, 1998, p. 119) and is based on a trusting relationship. With the increase in distrust, lack of long-term loyalty, less than secure employment, and increased complexity in organizational relationships, it appears reasonable to expect the commitment relationship between followers and the organization to change. "In the age of new deals and the change in the employee psychological contract, it would be unreasonable to expect the kind of OC (organizational commitment) which we new [sic] in the past" (Baruch, 1998, p. 137). In that it seems clear the bond between employee and the organization has been changed, this study argued it would be a more reasonable concept to assess follower commitment to the leader's vision.

Followers who are motivated and emotionally engaged in support of the leader's vision and goals commit at higher levels than unmotivated followers do, as they have a focus for their commitment and that is usually the leader (Bennett \& Durkin, 2000).

The concept of commitment in the workplace is changing from a focus on commitment to the organization, to follower's commitment to leader-led vision and goals. Changes in economic conditions, market changes, and changes in how work is done in organizations have caused the psychological contract between followers and the organization to be rewritten (Baruch \& Hind, 1999; DeMeuse \& Tornow, 1990; Westwood, Sparrow \& Leung, 2001;). This transition represents a change in the psychological contract and follower motivations.

Regardless of the nature of commitment, all commitments must have an object or focus by which a commitment is made (Brown, 1996). According to Brown, commitment develops from the combined elements of attitude, behavior, and normative forces. Brickman (1987) argued there were two sides to commitment: a positive want to and a negative have to. He further suggested that when there is a positive want to approach to commitment, the result is enthusiastic flow in one's work. When one experiences the negative have to in their commitment approach, the flow of their work is merely persistent effort.

\section{Motivation}

Motivational theorist Maslow's (1954) hierarchy of needs is a well-known and often used motivational theory. His theory purported unfulfilled needs act as motivations and these individual needs were hierarchal in nature. He posited that as lower needs were satisfied, individuals would be motivated to achieve higher-level needs until they reached self-actualization.

Since the inception of Maslow's (1954) theory, there have been multitudes of motivation theories introduced, most notably in the field of social science and organizational behavior. Some have found Maslow's hierarchal theory inadequate (Hood, 2003). Hall and Nougaim (1968) suggested Maslow's theory was not inclusive of cultural norms, individual differences, and expectations. McGregor (1960) believed there were only two motivating factors that determined how leaders motivated followers. Leaders were either Theory X or Y. Theory X leaders assumed followers wanted to be told what to do while Y leaders were more motivational in helping followers accomplish goals, believing human beings wanted to grow, evolve, and develop their skills in a constant attempt to self-actualize. Maslow (1968) argued:

Growth is seen, then, not only as a progressive gratification of basic needs to the point where they disappear, but at a more advanced level of development, taking the form of specific growth motivation over and above these basic needs, including talents, capacities, creative tendencies, and constitutional potentialities. (p. 24)

There appears to be little concurrence in the literature regarding a common theme or agreement in the use of the term motivation. It is also unclear what the common distinctive elements of motivation include. Ford (1992) attempted to integrate multiple theories of motivation into a Motivational Systems Theory (MST) similar in application to organizational systems theory. Ford posited there were organized patterns within motivational 
processes. He further argued that motivation is an integrated construct that represents the direction an individual is headed. This includes the emotional energy and affective experiences that would help or hinder movement in that direction and the expectation one has as to whether they will be able to accomplish the goal.

\section{Organizational Change}

"It must be considered that there is nothing more difficult to carry out nor more doubtful of success nor more dangerous to handle than to initiate a new order of things" (Machiavelli, 1446-1507). Organizational change is one of the most challenging and difficult strategies to manage in rapidly changing and consistently adapting organizations today. Turbulence marks the atmosphere as leaders desperately look for ways to decrease the threat to their competitiveness, refine their business strategies, and ensure their standing in the marketplace (Abraham, 2000). Beer and Nohria (2000, p. 133) argued as much as $70 \%$ of the time change strategies fail. This high rate of failure in change initiatives has been linked to a decrease in organization performance, loss of revenue, and a loss of standing in the market.

Very early on, Kotter and Schlesinger (1979) argued that change threatens an individual's self-interests and upsets the balance based on the status quo. Change managed incorrectly often leads to emotional instability, loss of morale, and becomes a drain on resources as a result of changes in relationships. Beer and Nohria (2000) determined change, whatever the type, often manifests its trauma in the form of loss to human and economic resources. Huy (1999) found the emotional dynamics of organizational change are required for change to occur. "The degree of an organization's ability to execute effectively these various emotional dynamics determines its level of emotional capability and, therefore, its likelihood of realizing radical change" (Huy, 1999, p. 332).

The question now becomes, "whose responsibility is it to motivationally and inspirationally affect the organization's ability to transform itself"? Kotter (1990) "But for leadership, achieving a vision requires motivating and inspiring - keeping people moving in the right direction, despite major obstacles to change, by appealing to basic but often untapped human needs, values, and emotions" (p. 104). It appears that it is the leader's responsibility to release the motivational energy for followers to commit to change initiatives.

Bennett and Durkin (2000) argued that internalized affective or emotional commitment has been found to be positively associated with successful organizational change. Demers, Forrer, Leibowitz, and Cahill (1996) argued, "Organisations [sic] tend to be very good at planning and orchestrating the technical and structural aspects of change, but poor at guiding and supporting the human side - the personal reorientation associated with change" (p. 22). Huy (1999) argued that people want to find meaning in change and want to be able to find their place in the change. Due to the emotional nature of change, Huy also suggested that since emotional investment frames meaning, change without attending to the emotional dynamics of change could negatively trigger strong emotions against the planned transformation.

When change failures occur, Abraham (2000) believed this caused employees to feel alienated, betrayed, and ultimately disappointed. As a result, cynicism develops and further reduces clarity of vision, and confidence in future changes. In turn, cynicism toward change becomes a self-fulfilling prophecy in that gets in the way of trusting in and participating fully in future change efforts, thus increasing the likelihood the change effort will fail. Given the uncertainty that accompanies change, Huy (1999) argued that emotional energy would be necessary to mobilize and charge followers and the organization. In order to compensate for the negative effects of cynicism, Kotter (1990) proposed:

Since change is the function of leadership, being able to generate highly energized behavior is important for coping with the inevitable barriers to change. Achieving grand visions always requires an occasional burst of energy. Motivation and inspiration energize people, not by pushing them in the right direction as control mechanisms do but by satisfying basic human needs for achievement, a sense of belonging, recognition, self-esteem, a feeling of control over one's life, and the ability to live up to one's ideals. Such feelings touch us deeply and elicit a powerful response. (p. 107) 
Denham et al. (2000) studied 25 companies and found there were three factors that would determine the correct change strategy for an organization. They were: the organization's overall performance, the leader's vision and preferences, and the organizational level of energy that could suffice for the type of change the organization planned to achieve. According to Denham et al., change programs should be expected to fail unless leaders are able to "release and funnel energy" (p. 30). Once followers' sources of energy and commitment are engaged, the process of transformation then begins. As discussed earlier, it has been proposed that the release of motivational energy may lead to increased follower commitment to leader-led change initiatives.

\section{PURPOSE OF THE STUDY}

This was a study about leadership from the follower's perspective. The purpose of this quantitative correlational research study utilizing the Emotional Competence Inventory (ECI@) Self Rater and 360 and the PQi@ Follower Commitment Instrument was to examine follower perceptions of 100 mid-level leaders in the electronic publishing industry located in the Northern United States. Those meeting the criteria of having the title of manager or director and a minimum of five direct reports were invited to examine the follower commitment theory by comparing perceived leader emotional competence to follower commitment. The purpose of this research study was to examine the follower commitment theory that leaders with high levels of emotional competence are able to increase follower commitment.

\section{Research Question}

This study was guided by the following research question: What is the relationship between follower perceptions of the mid-level leader's emotional competence and follower commitment?

\section{Research Hypotheses}

$\mathbf{H}_{\mathbf{0}} \quad$ There is no statistically significant relationship between follower perceptions of leader emotional competence and follower commitment.

$\mathbf{H}_{1}$ There is a statistically significant relationship between follower perceptions of leader emotional competence and follower commitment.

\section{RELIABILITY AND VALIDITY}

Survey reliability (internal consistency) and validity (construct validity) are key assumptions that required verification in every research study. The larger sample (mentioned earlier) was reduced to match leader and follower data sets. Follower scores were aggregated, and a mean follower score for each leader was calculated. This subsample of data was analyzed in order to assess the reliability and validity of the three instruments used.

A note of caution is required with respect to generalizing the results used in this study and to the assessment of the instruments analyzed. This caution is noted with respect to the ECI Self and 360 inventories. The publisher of the instruments maintains that up to $25 \%$ of the questions may be responded to with a don't know or na answer without materially affecting the overall measure of emotional competence. Because the publisher's development scaling weights were not available to allow an evaluation of the scales and sub-scales, only the composite scores were used in this analysis.

\section{Reliability}

Cronbach's alpha measures the degree to which results from the administration of an instrument could be replicated if the same individuals were tested again under similar circumstances (Crocker \& Algina, 1986). The PQi instrument was determined to be reliable since its alpha coefficient met the prescribed acceptance criteria (alpha $=$ .97). The ECI360 instrument was also deemed to be acceptable since its alpha coefficients (alpha $=.98$ ) also met the prescribed standard. The ECI Self instrument, on the other hand, was deemed unreliable for this study since three 
alpha coefficients were below the lowest acceptance threshold of .60. This would suggest since the ECI Self was found to be less reliable, this instrument should be treated with caution.

\section{Construct Validity}

Construct validity measures the degree to which an instrument measures what it intended to measure. In this case, the question of construct validity concerns the degree to which the instruments accurately measured emotional competence (ECI Self and ECI360) and follower commitment (PQi). Because the instrument publisher of the ECI did not make the proprietary developmental scaling formulas available, no additional sub-scale analysis could be performed on these instruments.

Regarding the PQi survey, construct validity of the instrument was marginally acceptable. The number of significant factors exceeded the single factor asserted by the author of the instrument. The first factor contained a high number of items that loaded with high factor loadings. This suggested not only the possibility of a single factor accounting for an average of all items on the questionnaire, but also that there may be a secondary structure among the 47 items. As a result, construct validity of the PQi instrument was found to be acceptable at the minimum standard. The possibility of a second structure within the instrument is noted for future investigation while acknowledging its use as a single factor instrument in this study.

\section{Data Analysis And Collection}

Descriptive statistics and bivariate analysis were used to compile and analyze the data. Two data samples were available to analyze. Useable results were obtained for 83 followers whose leaders also provided useable results. An additional group of 50 followers provided useable results, but for reasons unknown, their leaders did not provide useable results. Therefore, unless otherwise indicated, the $\mathrm{N}$ of these tables of data is 83 .

\section{Data Collection}

Of the 100 mid-level leaders invited to participate, 59\% returned consent forms and completed the ECI Self survey. Leaders completing the assessment that could not be matched to at least one follower were eliminated. This resulted in the elimination of nine leader scores. Of the 300 followers invited to participate, 158 returned consent forms and completed the ECI 360 and PQi survey instruments via online delivery, resulting in a 53\% return rate. Of the completed surveys, 25 were eliminated from analysis because survey results failed to meet the $25 \%$ response rule established by the publishers of the instrument for dealing with Don't Know answers. No mid-level leaders were eliminated for failing to meet the $25 \%$ rule.

\section{FINDINGS}

In order to answer the research question what is the relationship between follower perceptions of the midlevel leader's emotional competence and follower commitment, mean scores were averaged from the ECI360 and PQi and used to test the null hypotheses.

Table 1 is a correlation matrix depicting the strength of the relationship between all the variables. The relationship between the ECI360 and the PQi is statistically significant $(r=0.849 ; \mathrm{p}<.001)$. The matrix also depicts that the relationship between ECI Self and follower commitment (PQi), while more modest, is also significant $(r=$ $0.224 ; \mathrm{p}<.05)$. No other variable showed a statistically significant correlation to follower commitment (PQi). 


\begin{tabular}{llllll}
\multicolumn{5}{c}{ Table 1: Correlation Matrix of all Variables } \\
\hline & $\begin{array}{l}\text { Time with } \\
\text { leader }\end{array}$ & PQi & ECI360 & ECI Self & $\begin{array}{l}\text { Time in } \\
\text { position }\end{array}$ \\
\hline PQi & 0.103 & & & & \\
ECI360 & 0.043 & $0.849^{* * *}$ & & & \\
ECI Self & 0.156 & $0.224^{*}$ & $0.269^{*}$ & & \\
Time in pos & $0.673^{* * *}$ & 0.045 & 0.068 & 0.065 & \\
Time w/ org & $0.375^{* *}$ & 0.059 & 0.081 & 0.008 & $0.504^{* * *}$ \\
\hline
\end{tabular}

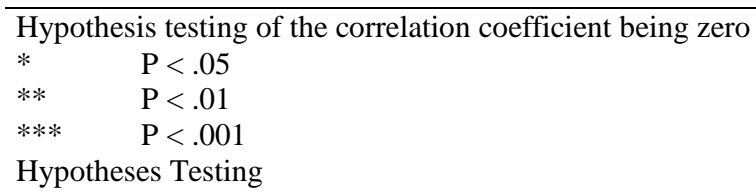

The null hypothesis (H0) of this study stated: there is no statistically significant relationship between follower perceptions of leader emotional competence and follower commitment. Conceptually, since follower perception of a leader's emotional competence was believed to be closely related to follower commitment, interest was first drawn to examining the results from the ECI360 and the PQi inventory results. The ECI360 and the PQi showed a statistically significant correlation of 0.849 . Based on the results of the tested data, the null hypothesis (H0) was rejected and the alternate hypothesis $(\mathrm{H} 1)$, that there is a statistically significant relationship between follower perceptions of leader emotional competence and follower commitment, was supported.

\section{Leader Emotional Competence (ECI Self)}

An assumption was made that since this study was to determine commitment from the follower's perspective, using ECI 360 data would be a more reliable measurement of leader emotional competence than ECI Self. Leaders were invited to participate in the study as a means of comparing self perceptions to follower perceptions of leader emotional competence, as leaders could not accurately assess follower commitment, nor did they take the PQi. Given the more modest relationship between ECI Self and follower commitment as depicted in Table 3, it seemed appropriate to assess whether there was a relationship between these two measures.

The two measures of ECI360 and ECI Self that are most noticeably different are at the extremes of their distribution, as shown in Table 2. Leaders whose followers rated them lowest tended to rate themselves much more favorably, and leaders whose followers rated their leaders highest tended to rate themselves much more modestly. The following table of aggregated data illustrates this pattern. Of the 11 followers who rated their leader in the lowest range, only one leader self-rated in the lower category. Conversely, of the 17 followers who rated their leaders in the highest category, only three leaders rated themselves in that higher level. The correlation indicates that two variables are related; the chi square test of independence, however, says they are independent. One variable does not predict the other. In summary, it appears that the ECI Self report, alone, would not be a good predictor of either ECI 360 or of follower commitment (PQi).

Table 2: ECI 360 and ECI Self

\begin{tabular}{lllll}
\hline & ECI Self & ECI Self & ECI Self & Total \\
\hline ECI 360 & $0-2.99$ & $3.0-3.49$ & 3.5 and over & \\
$0-3.499$ & 1 & 10 & 0 & 11 \\
$3.5-3.999$ & 5 & 17 & 3 & 25 \\
$4.0-4.49$ & 3 & 20 & 7 & 30 \\
4.5 and over & 3 & 11 & 3 & 17 \\
\hline Total & 12 & 58 & 13 & 83 \\
\hline Chi-Square $=5.207, \mathrm{DF}=6$, P-value $=0.518$ & &
\end{tabular}




\section{Time Variables and PQi}

The null sub-hypothesis (H0) was that a follower's time with their leader would not influence follower commitment (PQi). The alternate hypothesis (H1) stated that a follower's time with the leader would influence follower commitment. Evidence presented through testing showed no statistically significant relationship between the variable time with leader and follower commitment. While the time variables were correlated, no statistically significant relationship was found when time variables were measured against follower commitment or emotional competence, thereby leading to accepting the null sub-hypothesis. Since no significant relationship was found between time with leader and follower commitment, the alternate sub-hypothesis was accepted.

Regression analysis was performed to examine the predictive relationship between ECI360 and follower commitment. Multiple regression analysis provided no additional findings that would suggest variables other than ECI360 had any predictive value to explaining follower commitment. Time variables, in general, lacked significant correlation and offered little additional insight into follower commitment.

\section{Discussion Of Analysis}

The most significant and important finding was the strong statistical correlation between ECI 360 and PQI (leader emotional competence and follower commitment - see Figure 1). This finding should not be mistaken for a causal relationship. The fact that there is this strong correlation only permits the researcher to assume that variables are correlated. Further study utilizing a true experimental design is needed to determine a cause or causes for follower commitment. This does however, fully support the intent of this study, which was to determine whether there is a significant relationship between perceived leader emotional competence and follower commitment.

Given this strong correlation, it might be assumed that leaders who have higher levels of emotional competency could potentially experience higher levels of follower commitment. At least, the perception might be made that leaders with higher levels of emotional competence as perceived by their followers may experience a higher level of commitment as the effect size between these two variables was large.

Results of the study indicate that to become an effective leader, it is critical for leaders who are perceived as having lower levels of emotional competence find a way to learn to deal with understanding and relating to emotional behaviors. Leaders found to be predator-like, or have ruthless desires to control others, may benefit from the development of their emotional competencies through an established program designed to help overcome these barriers. Aggressive leaders, narcissistic leaders, or rigid and unbending leaders could be specific targets that could benefit from learning how to unlearn these negative emotional behaviors.

\section{Leader Self Assessment}

There were several assumptions made during the study. It was assumed that the surveys were valid and reliable instruments that could be used to measure emotional competence. This assumption was proven in part to be invalid. An assessment of the construct validity for the instruments showed the ECI Self was poor, the ECI360 was marginal, and the PQi was acceptable. The poor testing of ECI Self might have been expected due to the very nature of self-assessments.

Burckle (2000) studied 427 individuals from various organizations and assessed their ability to assess themselves. He reported that those who were found lower in accurate self-assessment by others tended to overrate themselves, and those who were rated higher in accurate self-assessment by others tended to underrate him or herself. This significant fact was noted in this study. Leaders who tended to rate themselves lowest were rated higher by their followers, and those mid-level leaders who rated themselves highest tended to be rated by their followers with lower ECI360 scores. Perhaps humility should be considered an element of emotional competence. 


\section{Follower Time with Leader}

The fact that $66 \%$ of followers have been with their leader less than 2.5 years, while $52 \%$ of mid-level leaders have been in their position more than 2.5 years, could suggest that there is a distinct difference in perception of commitment between these two groups. Time with leader showed no major correlation, suggesting that this variable may not have influenced the follower's perception of their leader's perceived emotional competence, and therefore their level of commitment as might have been expected. Of the $66 \%$ of followers having 2.5 years or less time with their leader, more than $50 \%$ of them had less than 1 year with the leader. The extremely small correlation found between the follower time with leader variable and follower commitment (PQi) suggests this variable is skewed. If there were a more even distribution of this sample, time with leader might have shown a stronger correlation.

This phenomenon may indicate that a pattern potentially exists within this organization of higher than expected turnover. If true, then the issue of follower commitment may be tied to high turnover and low retention. This variable of time with leader demonstrated enough interest that it warrants further investigation.

What remains unknown is whether follower time with leader may have influenced PQi, or whether perceived ECI360 influenced commitment, or whether a combination of follower time with leader and perceived ECI360 is responsible for this small but unique correlation. Further study is required to flush out more data of this variable.

\section{Recommendation To Organizations}

Business and related literature market is replete with information on leadership, motivation, and organizational commitment theories. Contemporary leaders are consistently looking for ways they might create the type of environment where follower commitment and motivations are released and used in support of the leader's vision and goals. Hesselbein (2000) argued it is the leader's job to motivate his or her followers. Motivational energy is available in every individual. Given the strength of the statistical significance between perceived leader emotional competence and follower commitment, it seems reasonable that learning to effectively deal with emotional issues in the workplace is a valuable and certainly critical undertaking.

There is a battle for followers' energies and commitment. Katzenbach and Santamaria (1999) believed, 'If there is one challenge that confounds the many organizations that depend on frontline workers, it is how to engender their emotional energy" (p. 107). Emotions are no longer the back seat driver in the vehicle of critical thinking and decision-making. It seems that mid-level leaders have the responsibility more than any other leader group to make the emotional connection work.

One way to accomplish this may be through the development of leader emotional competence. Emotional competence provides us answers to the questions of whether leaders are able to manage the interactions they have with others in order to constructively reach their deliverables. Emotional competence suggests that leaders with higher levels of emotional competence are able to manage their behaviors and identify emotional behaviors in others. Leaders who fail to do this may face economic uncertainty and higher levels of failures.

In a series of studies reported by TalentSmart (2004), it was found that Hallmark staff who developed emotional competence were $25 \%$ more effective that those who did not. The same series reported that the development of emotional intelligence competencies were responsible for an increase in productivity by $20 \%$ at AT\&T, while a multinational consulting firm increased profits by $139 \%$ (p. 4) because senior partners who were responsible for these large gains measured significantly higher in emotional competence.

When leaders who are positioned at every level within the organization learn the importance of not just building teams, but building interactive, integrated, and interconnected teams that work, a major step has been taken to release emotional energy and develop follower commitment. This requires a culture that has evolved to support emotional competence and is structured to support change initiatives that are needed to remain competitive. 


\section{CONCLUSION}

There is a new model of leadership that focuses on building relationships between leaders and followers in a way that increases follower commitment to leader-led goals. This research study suggests this leadership model requires a more emotional framework than the traditional rational approach to leading. The findings of this study would imply there is reasonable data to suggest that the mid-level leader's emotional competence may play a significant role in supporting this new model of relationship leading. Further, the role of emotional competence as it relates to follower commitment suggests that increased levels of commitment for leader-led change initiatives and goals are enhanced from more committed relationships, creating higher levels of success for change programs.

What has become clearer during this study is that how an individual feels about their work and the relationships engaged in their work life significantly impacts them and their productivity. LeDoux (1998) believed, "Once emotions occur they become powerful motivators of future behaviors" (p. 19). The concept of commitment in the workplace has changed from a focus on commitment to the organization, to follower commitment for leader-led vision and goals. This transition represents a change in the psychological contract and follower motivations, and is supported by the strong correlation between the ECI360 and the PQi.

Leaders who are hoping to experience greater levels of commitment to their change strategies, changing visions, and enhanced goals may greatly benefit from learning to understand, appreciate, and practice emotionally competent leadership. Given the argument that a very high percentage of all change initiatives fail and that the lack of commitment by followers in the workplace is estimated to cost organizations billions of dollars, it seems more than reasonable to conclude that emotionally competent leadership would become a highly recommended and prized strategic initiative in many organizations.

\section{ACKNOWLEDGMENT}

A special thanks to the organization that participated in this research project and an extra special thanks to the Sr. Vice President of Human Resources for making it possible to work with this organization.

\section{REFERENCES}

1. Baruch, Y. \& Hind, P. (1999). Perpetual motion in organizations: Effective management and the impact of the new psychological contracts on "survivor syndrome. European Journal of Work and Organizational Psychology. 8 (2), 295

2. $\quad$ Bass, B. M. (1985). Leadership beyond expectations. New York: Free Press.

3. Baruch, Y. (1998). The rise and fall of organizational commitment. Human Systems Management. 17(2), 135.

4. Beer, M. \& Nohria, N. (2000). Cracking the code of change. Harvard Business Review. 78 (3), 133.

5. Bennett, H. \& Durkin, M. (2000). The effects of organizational change on employee psychological attachment. Journal of Managerial Psychology. 15 (1/2), 126.

6. Bennis, W. G. \& Nanus, B. (1985). Leaders: The strategies for taking charge. New York: Harper \& Row.

7. Brickman, P. (1987). Commitment, conflict, and caring. Englewood Cliffs: Prentice-Hall.

8. Brown, R. B. (1996). Organizational commitment: Clarifying the concept and simplifying the existing construct typology. Journal of Vocational Behavior. 49, 230-251.

9. Burckle, M. (2000). Can you assess your own emotional intelligence? Evidence supporting multi-rater assessment. Boston: Hay/McBer Research Report.

10. Carlyle T. (1841/1907). Heroes and hero worship. Boston: Adams.

11. Crocker, L. \& Algina, J. (1986). Introduction to classical and modern test theory. Belmont, CA: Wadsworth Group.

12. Cross, R., Baker, W., \& Parker, A. (2003). What creates energy in organizations? MIT Sloan Management Review. 44 (4), 51.

13. DeMeuse, K. P. \& Tornow, W. W. (1990). The tie that binds has become very, very, frayed. Human Resource Planning. 13(3), 203. 
14. Denham, M., Blackwell, N., \& Dickhout, R. (2000). Designing the right change program for you and your organization. Ivey Business Journal. 64 (5), 26.

15. Ford, M. E. (1992). Motivating humans: Goals, emotions and personal agency beliefs. Newbury Park: Sage Publications.

16. Frankl, V. E. (2000). Man's search for ultimate meaning. New York: Perseus Publishing.

17. French, J. R. P. \& Raven, B. (1959). The bases of social power. In D. Cartwright (Ed.), Studies in social power. Ann Arbor: University of Michigan, Institute for Social Research.

18. Galton F. (1869). Hereditary genius. New York: Appleton.

19. Goleman, D. (1998). Working with emotional intelligence. New York: Bantam Books.

20. Gregersen, H. B., Morrison, A. J., \& Black, J. S. (1998). Developing leaders for the global frontier. Sloan Management Review. 40(1), 21.

21. Hall, D. T. \& Nougaim, K. E. (1968). An examination of Maslow's need hierarchy in an organizational setting. Organizational Behaviour and Human Performance. 3, 12-35)

22. Heffes, E. M. (2003). Energy: The currency of personal productivity. Financial Executive. $19(7), 39$.

23. Hesselbein, F. (2000). Organizational leadership in the twenty-first century. Reflections. 2,1,52-56.

24. Hood, P. J. (2003). Human resource development: Motivation and movement. Management in Education. $16(4), 19$.

25. Humphreys, J. H., Weyant, L.E., \& Sprague, R. D. (2003). Organizational commitment: The roles of emotional and practical intellect within the leader/follower dyad. Journal of Business \& Management. 9(2), 189.

26. Katzenbach, J. R. \& Santamaria, J. A. (1999). Firing up the front line. Harvard Business Review. 77 (3), 107.

27. Kielson, D. C. (1994). Getting to success: Efficient energy use. Management Review. 83 (12), 47.

28. Landen, M. (2003). Citizenship or careerism: Perceptions and impressions of goodness. Department of Economics and Human Resource Management: Leeds Business School.

29. LeDoux, J. (1998). The emotional brain: The mysterious underpinnings of emotional life. New York: Touchstone.

30. Lewin, K. \& Lippitt, R. (1938). An experimental approach to the study of autocracy and democracy: A preliminary note. Sociometry, 1, 292-300.

31. Lucas, J. R. (1999). The passionate organization: Igniting the fire of employee commitment. New York: AMA Publications.

32. Maslow, A. (1954). Motivation and personality. New York: Harper \& Row.

33. Maslow, A. (1968). Toward a psychology of being. New York: Litton.

34. Mayo, E. (1949) Hawthorne and the Western Electric Company: The social problems of an industrial civilization. London: Routledge.

35. McClelland, D. (1973). Testing for competence rather than for intelligence. American Psychologist. 28 , 1-14. Retrieved March, 2004.

36. McGregor, D. M. (1960). The human side of enterprise. New York: McGraw-Hill.

37. Meyers, J. P. \& Allen, N. J. (1991). A three-component conceptualization of organizational commitment. Human Resources Management Review. 1 (1), 61-89.

38. Noble, C. H. \& Mokwa, M.P. (1999). Implementing marketing strategies: Developing and testing a managerial theory. Journal of Marketing. 63(4), 57.

39. Mowday, R. T., Porter, L. W., \& Steers, R. M. (1979). The measurement of organizational commitment. Journal of Vocational Behavior. 14, 224-247.

40. Nicholson, N. (2003). How to motivate your problem people. Harvard Business Review. 81(1), 56. Retrieved June 2003, from EBSCOHost database.

41. Ostwald, W. (1903). The philosophical meaning of energy. International Quarterly. 7, 300-315.

42. Overton, B. J. \& Burkhardt, J. C. (1999). Drucker could be right: New leadership models for institutionalcommunity partnerships. Applied Developmental Science. 3(4), 217.

43. Rajput, J. S. (1999). Education in a changing world: Fallacies and forces. New Delhi: Vikas.

44. Roethlisberger, F. J. (1941/2001). The Hawthorne experiments. In J.M. Shafritz \& J.S. Ott (Eds.). Classics of organization theory (5th ed., pp. 158-166). Belmont: Wadsworth Group. (Original work published 1941). 
45. Schwartz, H. S. (1990) Feelings as information: Informational and motivational functions of affective states. In E.T. Higgins \& R. Sorrentino (Eds.). Handbook of motivation and cognition: Foundations of social behavior (pp. 527-561). New York: Guildford.

46. Senge, P. M. (1990). The fifth discipline: The art \& practice of the learning organization. London: Random House.

47. Slater, R. (2001). Get better or get beaten. New York: McGraw-Hill.

48. Teal, T. (1996). The human side of management. Harvard Business Review. 74 (6), 35. .

49. Werhane, W. \& Maitland, R. (2002). U.S. employees rank low on commitment to current employers: Out of top 10 global economies, U.S. places $6^{\text {th }}$ in commitment levels. ISR Research Services.

50. Westwood, R., Sparrow, P., \& Leung, A. (2001). Challenges to the psychological contract in Hong Kong. International Journal of Human Resource Management. 12 (4), 621-651. 


\section{$\underline{\text { Notes }}$}

